\title{
Albumin Reduces Blood-Brain Barrier Permeability But Does Not Alter Infarct Size in a Rat Model of Neonatal Stroke
}

\author{
RONG WANG, STEPHEN ASHWAL, BEATRIZ TONE, HOU ROU TIAN, JEROME BADAUT, ALISON RASMUSSEN, \\ AND ANDRE OBENAUS
}

\begin{abstract}
Department of Radiation Medicine [R.W., A.R., A.O.], Department of Pediatrics [S.A., B.T., H.R.T.], Loma Linda University School of Medicine, Loma Linda, CA 92354; Neurosurgery Research Group [J.B.], Centre Hospitalier Universitaire Vaudois, 1011 Lausanne, Switzerland
\end{abstract}

\begin{abstract}
Human serum albumin therapy confers neurobehavioral and histopathologic neuroprotection in adult stroke models. We investigated whether albumin might also be neuroprotective in ischemic brain injury using a transient filament middle cerebral artery occlusion (tfMCAO) model in 10-d-old rat pups treated with $0.25 \%$ albumin or saline $1 \mathrm{~h}$ after reperfusion. We performed serial neurobehavioral and magnetic resonance imaging (MRI) assessments immediately after tfMCAO (day 0) and on 1, 3, 7, 14, and $28 \mathrm{~d}$. IgG staining to assess blood-brain barrier (BBB) integrity and standard histology was obtained on 1, 3, and $28 \mathrm{~d}$. Hemispheric infarct volumes from MRI were similar in saline and albumin groups ( $0 \mathrm{~h}$ : $39 \%$ and $44 \%$; $\mathrm{d} 1: 46 \%$ and $55 \%$; and $\mathrm{d} 28: 10 \%$ and $24 \%$ ) as were neurobehavioral assessments. IgG staining at $3 \mathrm{~d}$ post-ischemia showed loss of BBB integrity that was significantly reduced after albumin. Elevated T2 values suggesting vasogenic edema was seen in albumin compared with saline-treated animals, as was increased water mobility (i.e. increased apparent diffusion coefficient (ADC) reflecting cytotoxic edema. The reasons why albumin was not neuroprotective in neonatal stroke compared with adults remain uncertain. Effective strategies in adult models need to be reassessed in the neonate. (Pediatr Res 62: 261-266, 2007)
\end{abstract}

A rterial ischemic stroke (AIS) occurs in 1 per 4000 neonates annually and results in neurologic disabilities such as hemiplegic cerebral palsy, language deficits, developmental delay, epilepsy and behavioral disorders (1). Pharmacologic intervention may be important in reducing brain injury and in improving outcomes in such neonates.

In adult rodent stroke models, albumin, an endogenous plasma protein with important physiochemical properties (2), has been considered a potential therapy. At high doses (1\% of body weight, i.v.), albumin treatment decreased infarct volume (by up to 66\%), diminished brain swelling $(3,4)$, ameliorated behavioral deficits, and improved local perfusion in affected tissue (5). Albumin was also effective at moderate doses $(0.25 \%-0.5 \%$ body weight $)$ with a broad therapeutic window that extended up to $4 \mathrm{~h}$ after stroke (6). The neuro-

Received January 16, 2007; accepted March 30, 2007.

Correspondence: Andre Obenaus, Ph.D., Radiobiology Program, CSP A1010, Department of Radiation Medicine, Loma Linda University, Loma Linda, CA 92354; e-mail: aobenaus@dominion.llumc.edu

Supported in part by the Pediatric Research Fund, Department of Pediatrics, a NASA Cooperative Agreement NCC9-149 to the Radiobiology Program, Department of Radiation Medicine at Loma Linda University, and to the Swiss Science Foundation (FN 3100AO-108001), Neurosurgery Research Group at Lausanne. protective effect of albumin has been attributed to hemodilution and lowering of blood viscosity that is hemodynamically beneficial to ischemic tissue $(7,8)$. However, albumin is a multifunctional protein and other mechanisms of action have been proposed (9). These include antioxidant activity (10), binding of transition metals (2), improvement of tissue perfusion (5), reduction of brain edema $(3,4)$, providing essential fatty acids to the injured brain (11), inhibiting endothelial apoptosis (12), and maintenance of normal astrocytic function (13). Phase I and II clinical trials in subjects with acute ischemic stroke have recently reported that higher doses of albumin correlated with better outcomes $(14,15)$, and a phase III trial has begun (16).

In neonates, albumin has been used in the fluid resuscitation of hypovolemia, although recent guidelines do not recommend its routine use (17-19). Because of albumin's neuroprotective role in adult rodent ischemic stroke models and its longstanding use in newborns, we hypothesized that albumin could be a potential neuroprotective agent after neonatal stroke. We examined whether albumin could reduce infarct volume and improve the biophysical properties of the infarcted tissue (T2 and $\mathrm{ADC}$ values) and integrity of the BBB after tfMCAO in 10-d-old rat pups.

\section{METHODS}

All protocols were approved by the Loma Linda University Medical Center Institutional Animal Care and Use Committee. Methods have been described in detail previously $(20,21)$.

tfMCAO. Focal ischemia was induced by temporary insertion of a filament into the left middle cerebral artery (MCA) in unsexed 10-d-old spontaneously hypertensive rat (SHR) pups $(14-18 \mathrm{~g} ; n=46)(21)$. Under anesthesia $(4 \%$ isoflurane), the left common carotid artery was clamped, the left external carotid artery was ligated, and a silicon-coated nylon filament (\#6, $0.07 \mathrm{~mm}$ ) was inserted $15 \mathrm{~mm}$ into the internal carotid artery to block the MCA. Pups recovered from anesthesia and were checked for neurologic deficits $90 \mathrm{~min}$ after occlusion. Just before MRI, pups were reanesthetized and the filament was withdrawn. During all surgical interventions and imaging, animals were maintained at $34 \pm 0.5^{\circ} \mathrm{C}$ via a feedback recirculating water blanket.

Treatment groups. At $1 \mathrm{~h}$ after tfMCAO, pups received human serum albumin (Baxter International; 25\% solution, $n=22$ ) i.v. (femoral vein) at $1 \%$ of the pup's body weight $(168 \pm 20 \mu \mathrm{L})$. Control pups $(n=24)$ received a comparable volume of $0.9 \% \mathrm{NaCl}(165 \pm 16 \mu \mathrm{L})$.

Abbreviations: ADC, apparent diffusion coefficients; BBB, blood-brain barrier; DWI, diffusion-weighted imaging; ROI, region of interest; tfMCAO, transient filament middle cerebral artery occlusion; T2WI, T2-weighted imaging 
MRI. MRI was performed immediately after filament withdrawal $(0 \mathrm{~h})$ and at $1,3,7,14$, and $28 \mathrm{~d}$ after stroke induction (21). Pups were lightly anesthetized using isoflurane (1.0\%) and were imaged on a Bruker Avance 11.7 T MRI (Bruker Biospin, Billerica, MA). Two imaging data sets were acquired: (1) a 10-echo T2 and (2) a diffusion-weighted sequence in which each sequence collected 20 coronal slices $(1 \mathrm{~mm}$ thick and interleaved by a 1 $\mathrm{mm})$. The T2 sequence had the following parameters: repetition time (TR)/ echo time $(\mathrm{TE})=4600 \mathrm{~ms} / 10.2 \mathrm{~ms}$, matrix $=128 \times 128$, field of view $(\mathrm{FOV})$ $=3 \mathrm{~cm}$, number of excitation $(\mathrm{NEX})=2$, and acquisition time $=20 \mathrm{~min}$. The spin echo diffusion sequence parameters were TR/TE $=3000 \mathrm{~ms} / 25 \mathrm{~ms}, b$ values $=0.72,1855.64 \mathrm{~s} / \mathrm{mm}^{2}$, matrix $=128 \times 128$, FOV $=3 \mathrm{~cm}$, NEX $=$ 2 , and acquisition time $=17 \mathrm{~min}$. At 28 -d, pups were imaged on a larger bore Bruker 4.7 $\mathrm{T}$ imager with identical imaging parameters.

Image analysis. Volumetric MRI analysis methods have been previously published (21). Briefly, using Amira software (Mercury Computer Systems, Inc.), T2- and diffusion-weighted images (DWIs) were analyzed from the entire data set using regions of hypo- or hyperintensity to delineate the spatial development of the infarct volume. Analysis included infarct brain volume (total, cortical, and striatal infarct), noninfarct brain volume, and total brain volume.

$\mathrm{T} 2$ and $\mathrm{ADC}$ values are quantitative measurements that respectively reflect the evolution of vasogenic and cytotoxic edema. All MR data sets were quantified using standard protocols published previously (22). T2 relaxation rates were determined for each pixel, and T2 maps were generated. ADC maps were calculated using a linear two-point fit. Two primary regions of interest (ROIs), cortex and striatum, in both ipsi- and contralateral hemispheres, were delineated on T2-weighted images (T2WI). These ROIs were then overlaid onto corresponding T2 and ADC maps and the mean, SD, number of pixels, and area for each ROI was extracted. MRI analysis was performed without knowledge of the treatment group.

Neurologic testing. A neurologic battery evaluating motor and exploratory behavior was used before tfMCAO and at $0 \mathrm{~h}$ and 1,3, 7, 14, and $28 \mathrm{~d}$ after injury (21). Open-field testing in a $92 \times 64-\mathrm{cm}$ box with 8 -cm high walls evaluated limb preference toward the paretic side, circling toward the paretic side, the righting reflex time for supine pups to return to a prone position, and forelimb and hindlimb placing for each limb in response to visual, vibrissae, tactile, and proprioceptive stimulation $(23,24)$. Data were expressed as the percentage of pups with abnormal scores.

Histology. At 28 d, five saline-treated and three albumin-treated pups were anesthetized (ketamine $90 \mathrm{mg} / \mathrm{kg}$, xylazine $10 \mathrm{mg} / \mathrm{kg}$ ) and perfused transcardially with $10 \%$ buffered neutral formalin solution (21). Brains were removed, postfixed, paraffin processed, and cut into $7-\mu \mathrm{m}$-thick sections that were mounted onto glass slides and stained with $0.1 \%$ cresyl violet acetate (22).

Histologic infarct area measurements were based on the largest infarct area. Sections were digitally captured (three sections per animal) and ROIs included infarct, noninfarct, and total brain area. When tissue loss or ventricular size increase was observed, the contralateral ROIs were mirrored onto the injured tissue and the percentage of infarct area was calculated (21).

IgG staining. Sections for IgG staining were deparaffinized and immersed into citrate buffer ( $\mathrm{pH}$ 6.0) for $3 \mathrm{~min}$ in a pressure cooker for heat epitope retrieval. Sections were incubated with biotin-conjugated affinity purified donkey anti-rat IgG (Jackson Immunoresearch Inc.) diluted (1:200) in phosphate-buffered saline containing $0.1 \%$ Triton X-100 and $1 \%$ BSA for $4 \mathrm{~h}$ at room temperature. After washing, sections were incubated for $1 \mathrm{~h}$ at room temperature with streptavidin infrared dye $800 \mathrm{~nm}$ (1:400, Molecular Probes) and then scanned with an infrared scanner (Odyssey-System, LiCor, Germany) to quantify fluorescence in two ROIs (cortex and striatum) on two adjacent slices.

Statistical analysis. Weights, survival rates, and differences in T2 and ADC in saline- versus albumin-treated groups were compared using $t$ tests (SigmaStat, SPSS Inc., San Jose, CA, $p<0.05$ ) for each time point in all ROIs. Temporal evolution of T2 and ADC was tested using an analysis of variance (ANOVA). When significance $(p<0.05)$ was found a pairwise multiple comparison procedure (Tukey test, $p<0.05, p<0.01$ ) was performed for each time point to isolate differences. Temporal evolution of infarct volume measured from T2WI, DWI, and histologic sections was tested using one-way ANOVA $(p<0.05)$.

\section{RESULTS}

No significant differences in mean weight or $\%$ survival were observed between the two experimental groups (Table 1).

Serial DWI and T2WI. Representative serial T2WI and DWI from a saline- and albumin-treated rat pup are shown in Figure 1, highlighting differences in these two imaging modalities for monitoring infarct evolution. Ischemic changes with extensive confluent hyperintense lesions in the dorsal and lateral regions of frontal parietal cortex of the left hemisphere were observed immediately in both groups $(0 \mathrm{~h})$ with DWI, and these changes were maximal at $1-3 \mathrm{~d}$. From 7 to $14 \mathrm{~d}$, the DW images became more difficult to interpret because of the development of postnecrotic cavitation and encephalomalacia. Evidence of ischemic injury on T2WI lagged behind that seen with DWI and was maximal between d 3 and 7; a distinct pattern of postnecrotic cortical and subcortical remodeling was observed on $\mathrm{d} 28$.

T2 and $A D C$ values. Quantitative $\mathrm{T} 2$ relaxation times (ms) in albumin-treated pups were greater in all brain regions examined (cortex, striatum) compared with saline-treated controls, likely reflecting vasogenic edema formation (Fig. 2). In the ipsilateral cortex of albumin-treated pups, $\mathrm{T} 2$ values were increased by $22.3 \%$ at $1 \mathrm{~d}$ and $21.6 \%$ at $3 \mathrm{~d}$ compared with saline pups. T2 values were also increased in the ipsilateral cortex in albumin-treated pups during the first $7 \mathrm{~d}$, reaching a maximum of $144.3 \pm 2.9 \mathrm{~ms}(1 \mathrm{~d})$, that then declined by $28 \mathrm{~d}$ to $68.7 \pm 8.7 \mathrm{~ms}$. This increase in cortical $\mathrm{T} 2$ values was

Table 1. Weight, \% survival, and ADC values in contra-/ipsilateral cortex or striatum

\begin{tabular}{|c|c|c|c|c|c|c|}
\hline & $0 \mathrm{~d}$ & $1 \mathrm{~d}$ & $3 \mathrm{~d}$ & $7 \mathrm{~d}$ & $14 \mathrm{~d}$ & $28 \mathrm{~d}$ \\
\hline \multicolumn{7}{|l|}{ Saline } \\
\hline \% Survival & $100 \%$ & $96 \%$ & $75 \%$ & $29 \%$ & $21 \%$ & $21 \%$ \\
\hline Avg. weight (g) & $16.5 \pm 1.6$ & $15.4 \pm 1.3$ & $15.4 \pm 3.0$ & $18.8 \pm 5.0$ & $42.4 \pm 2.8$ & $96.6 \pm 6.6$ \\
\hline ADC ipsilateral striatum & $35.8 \pm 1.0$ & $37.3 \pm 0.6$ & $43.1 \pm 1.5$ & $56.9 \pm 2.0$ & $49.5 \pm 1.8$ & $156.0 \pm 6.9 *$ \\
\hline ADC contralateral cortex & $68.8 \pm 0.0$ & $62.1 \pm 0.8$ & $51.0 \pm 0.8 \dagger$ & $53.9 \pm 0.7 \dagger$ & $41.7 \pm 0.8 \dagger$ & $84.7 \pm 2.8$ \\
\hline ADC contralateral striatum & $72.6 \pm 1.0 \dagger$ & $65.0 \pm 0.9 \dagger$ & $51.5 \pm 0.8 \dagger$ & $52.8 \pm 0.7 \dagger$ & $41.5 \pm 0.9 \dagger$ & $100.0 \pm 4.8^{*}$ \\
\hline Avg. weight (g) & $16.8 \pm 2.0$ & $15.8 \pm 1.9$ & $14.6 \pm 2.4$ & $18.0 \pm 5.7$ & $32.6 \pm 13.3$ & $80.7 \pm 6.0$ \\
\hline ADC ipsilateral cortex & $46.2 \pm 0.9$ & $40.2 \pm 0.8$ & $45.4 \pm 1.1$ & $47.7 \pm 0.9$ & $49.0 \pm 1.1$ & $171.3 \pm 3.0^{*}$ \\
\hline ADC ipsilateral striatum & $34.7 \pm 1.1$ & $33.2 \pm 1.0$ & $41.6 \pm 1.4$ & $65.5 \pm 2.0$ & $112.9 \pm 4.8^{*}$ & $225.6 \pm 9.3^{*}$ \\
\hline ADC contralateral cortex & $63.8 \pm 1.0$ & $59.5 \pm 0.8$ & $49.4 \pm 0.8$ & $46.8 \pm 0.7$ & $46.6 \pm 0.8$ & $74.6 \pm 2.4$ \\
\hline ADC contralateral striatum & $68.4 \pm 1.0$ & $59.4 \pm 0.9$ & $51.6 \pm 1.1^{*}$ & $49.3 \pm 1.1^{*}$ & $46.0 \pm 1.2^{*}$ & $91.1 \pm 3.2$ \\
\hline
\end{tabular}

Data presented as mean $\pm \mathrm{SD}$, ADC expressed in $10^{-3} \mathrm{~mm}^{2} / \mathrm{s}$.

*Different from ADC value at $0 \mathrm{~d}$.

$\dagger$ Different from ADC value at $28 \mathrm{~d}$. 


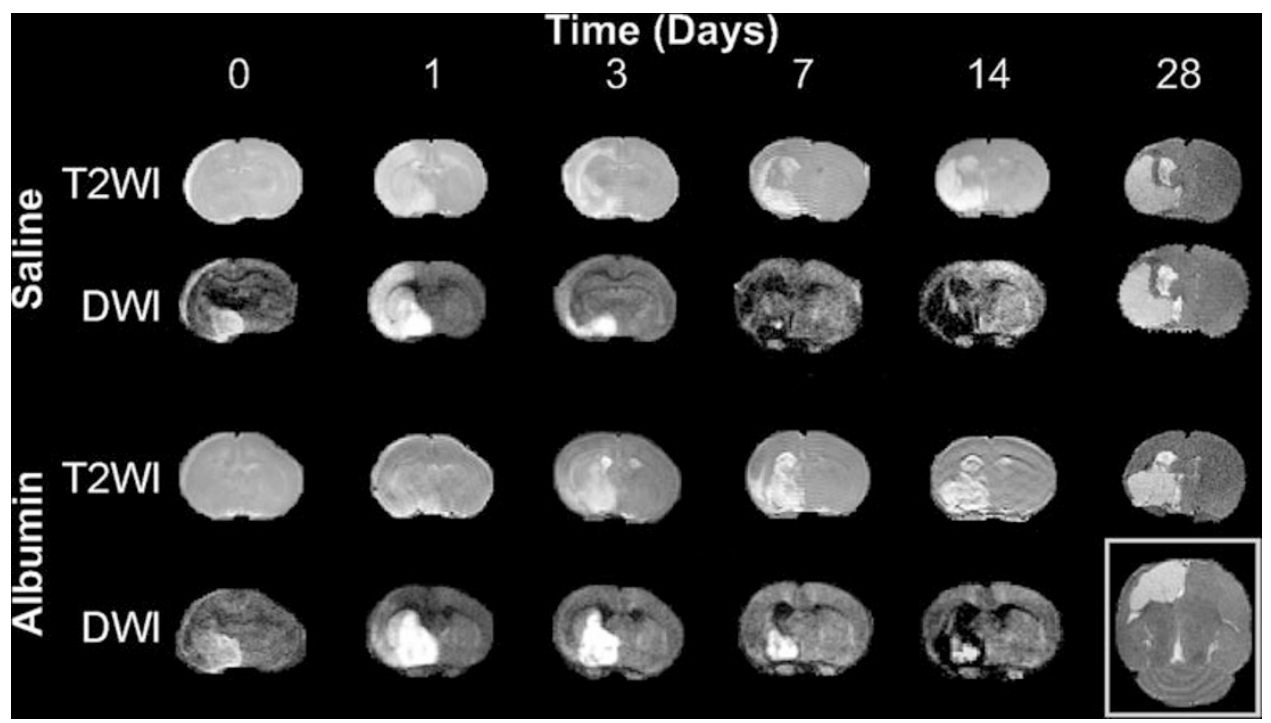

Figure 1. Serial neuroimaging in salineand albumin-treated animals. DWI clearly demarcates the onset of infarcted tissue within $1 \mathrm{~h}$ after stroke onset that becomes maximal at $1-3 \mathrm{~d}$ in both T2WI and DWI. The final infarct then slowly decreases in size over the next $28 \mathrm{~d}$ such that both T2WI and DWI report very similar infarct regions. An axial image from an albumin animal (inset box) illustrates the frontocaudal extent of the infarct lesion.

muted in saline-treated pups (Fig. 2). Within the ipsilateral striatum of albumin and saline pups, there was also a progressive increase in $\mathrm{T} 2$ that peaked at $14 \mathrm{~d}$ and declined by $28 \mathrm{~d}$ (Fig. 2). The temporal decline in $\mathrm{T} 2$ values was similar in the contralateral hemisphere of both groups.

No significant changes in ADC between saline or albumin treatment groups were observed at the early time points during the period that DWI most accurately visualizes cytotoxic edema formation. Although early temporal ADC changes were not detected, later time points (14 and $28 \mathrm{~d}$ ) showed significant increases in ADC in the ipsilateral cortex and the striatum of albumin-treated pups (Table 1), suggestive of ongoing vasogenic edema and/or tissue remodeling. Similar elevations of ADC were found in saline-treated pups at $28 \mathrm{~d}$ in the ipsi- and contralateral striatum but not cortex (Table 1). Finally, there was a temporal reduction in ADC 3-14 d after albumin treatment in the contralateral striatum.

Infarct volume measurement. Infarct lesion volumes from DWI were maximal on $\mathrm{d} 1$ in both groups and evolved over

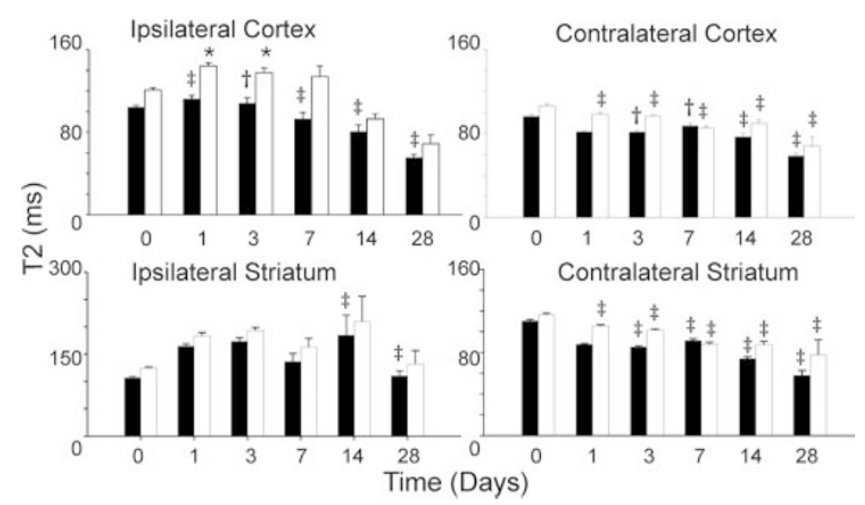

Figure 2. Quantitative T2 relaxation times (ms) from saline- (ם) and albumin- $(\square)$ treated animals. Animals treated with albumin have significantly higher $\mathrm{T} 2$ values in the ipsilateral cortex compared with saline-treated animals, suggesting increased cortical tissue water present in these animals at 1 and $3 \mathrm{~d}$. Although there were temporal effects present in the ipsi- and contralateral cortex, there was no significant difference in $\mathrm{T} 2$ values between saline- and albumin-treated animals. $* p<0.05$ comparisons to saline treated animals; $\ddagger p<0.05 ; \ddagger p<0.01$ comparisons with time. the next $28 \mathrm{~d}$. The final volumes, measuring $10.4 \pm 5 \%$ (saline) and $24.3 \pm 2 \%$ (albumin) were not significantly different (Fig. 3A). Infarct volumes measured from T2WI at later time points $(7-28 \mathrm{~d})$ revealed that infarct volume was similar at $7 \mathrm{~d}$ (saline $14.46 \pm 3.28 \%$; albumin $16.37 \pm 6.89 \%$ ) compared with 28 -d lesion volumes [12.17 $\pm 4.46 \%$ (saline) and $11.81 \pm 4.27 \%$ (albumin) (data not shown)].

Neurologic assessment. Maximum neurologic impairment in both saline and albumin treatment was seen at $\mathrm{d} 1$ after tfMCAO (Table 2). By 7 d, there were no observable neurologic deficits and all pups (saline or albumin) had normal neurologic scores despite imaging (Fig. 1) and histologic (Fig. 4) data showing large infarcts. The neurologic scores did not significantly differ between the two groups (two-way ANOVA; $p=0.11$ ).

Histopathology. Histologic sections revealed significant ipsilateral tissue loss in the cortex and striatum in both saline and albumin groups (Fig. 4). The contralateral tissue in both groups had normal-appearing parenchyma with no overt histologic differences. The infarct area averaged $30.1 \pm 9.5 \mathrm{~mm}^{2}$ in saline and $36.2 \pm 4.2 \mathrm{~mm}^{2}$ in albumin-treated pups (Fig. $3 B$ ). This represented infarct areas of $29.3 \pm 11.2 \%$ (saline)
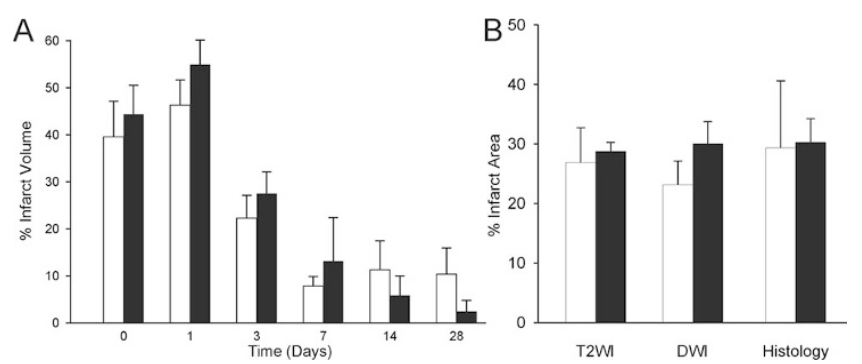

Figure 3. Comparison of infarct volume and area measured by $\mathrm{T} 2$ in saline- $(\square)$ and albumin- ( $\square$ ) treated animals. (A) No differences were found in total infarct volume from three-dimensional reconstructions of T2 data sets from either saline- or albumin-treated animals. Although there was a trend at 14 and $28 \mathrm{~d}$ for smaller infarct volumes in albumin-treated animals, this did not reach significance. $(B)$ At $28 \mathrm{~d}$, comparisons of infarct area between T2WI, DWI, and histology revealed no significant differences between these measurements types. 
Table 2. Percentage of animals with abnormal neurobehavioral testing (saline, $n=24$ albumin, $n=22$ )

\begin{tabular}{|c|c|c|c|c|c|c|c|}
\hline & $\begin{array}{l}\text { Before } \\
\text { MCAO }\end{array}$ & $\begin{array}{l}\text { After } \\
\text { MCAO }\end{array}$ & $1 \mathrm{~d}$ & $3 \mathrm{~d}$ & $7 \mathrm{~d}$ & $14 \mathrm{~d}$ & $28 \mathrm{~d}$ \\
\hline \multicolumn{8}{|c|}{$\begin{array}{l}\text { Open field } \\
\text { observations }\end{array}$} \\
\hline Saline & 0 & 7 & 18 & 7 & 0 & 0 & 0 \\
\hline Albumin & 0 & 6 & 12 & 0 & 0 & 0 & 0 \\
\hline \multicolumn{8}{|l|}{ Circling } \\
\hline Saline & 0 & 50 & 53 & 7 & 0 & 0 & 0 \\
\hline Albumin & 0 & 28 & 41 & 31 & 0 & 0 & 0 \\
\hline \multicolumn{8}{|c|}{ Righting reflex } \\
\hline Saline & 0 & 0 & 0 & 0 & 0 & 0 & 0 \\
\hline Albumin & 0 & 0 & 6 & 0 & 0 & 0 & 0 \\
\hline \multicolumn{8}{|c|}{$\begin{array}{l}\text { Forelimb and } \\
\text { hindlimb placing }\end{array}$} \\
\hline Saline & 0 & 0 & 0 & 14 & 0 & 0 & 0 \\
\hline Albumin & 0 & 0 & 0 & 0 & 0 & 0 & 0 \\
\hline
\end{tabular}

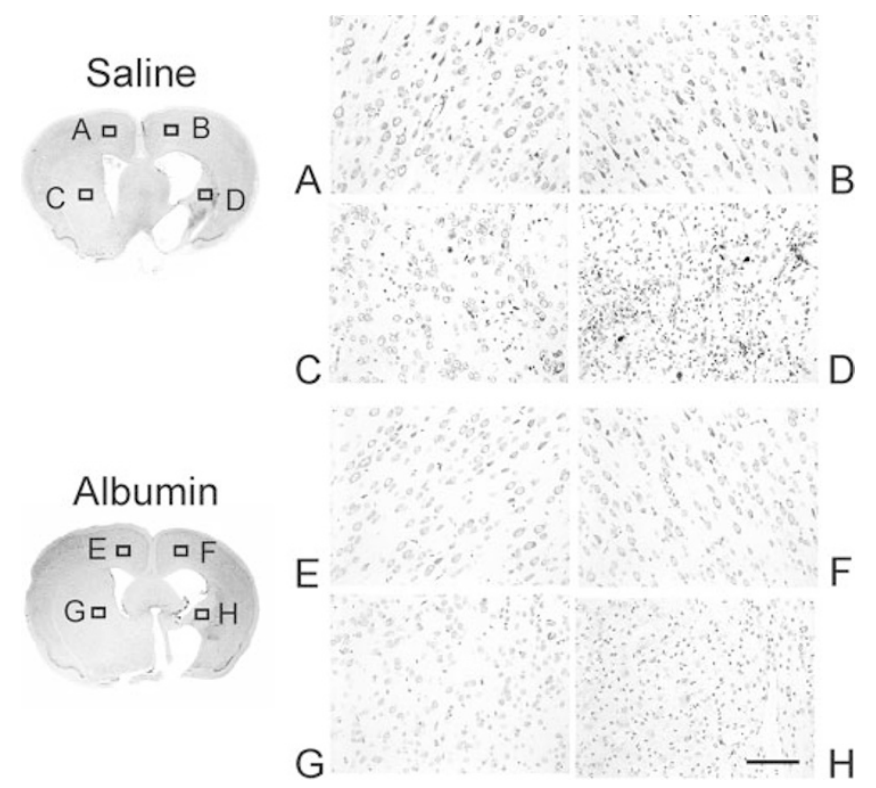

Figure 4. Cresyl violet histochemistry of saline- and albumin-treated pups at $28 \mathrm{~d}$ after stroke. Saline-treated pups showed healthy neurons within the contralateral cortex $(A)$ and striatum $(C)$. In the infarcted tissue, there is evidence of reduced density and pyknotic neurons in the ipsilateral cortex $(B)$ with significant cell loss and reduced density within the affected striatum $(D)$. Albumin-treated pups had similar findings in the contralateral cortex $(E)$ and striatum $(G)$. The ipsilateral ischemic cortex $(F)$ and striatum $(H)$ showed reduced density and the appearance of pyknotic neurons. Bar $=100 \mu \mathrm{m}$.

and $30.3 \pm 3.9 \%$ (albumin) of the total brain area. No significant differences were observed between the MRI and histologic measurement groups.

$\boldsymbol{I g} \boldsymbol{G}$ staining. BBB integrity was assessed using $\operatorname{IgG}$ immunohistochemistry. In saline-treated pups $1 \mathrm{~d}$ after stroke, IgG staining was increased in the ipsilateral striatum $(273 \% ; p<0.0001)$ and cortex $(163 \% ; p<0.001)$ compared with contralateral regions. At $3 \mathrm{~d}, \operatorname{IgG}$ staining was still increased in the striatum $(229 \%, p<0.001)$ and cortex $(217 \%$ $p<0.001$ ) (Fig. 5). The IgG staining measured within the cortex at $3 \mathrm{~d}$ continued to increase relative to $1 \mathrm{~d}$, suggesting that there is continuing evolution of BBB disruption.

In contrast, $\operatorname{IgG}$ staining intensities were not significantly elevated in the ischemic region compared with the contralat-

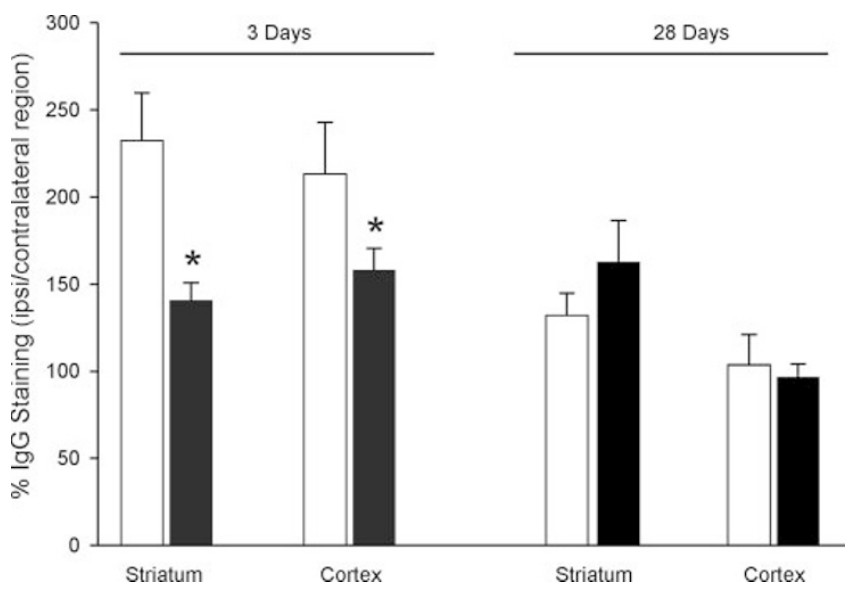

Figure 5. IgG staining for assessment of BBB disruption. Albumin treatment (ם) significantly decreases IgG staining at $3 \mathrm{~d}$ after stroke compared with saline-treated $(\square)$ animals. However, at $28 \mathrm{~d}$, there are no significant differences in staining between saline- and albumin-treated animals $\left({ }^{*} p<0.05\right)$.

eral region in the albumin-treated pups at $3 \mathrm{~d}$ (striatum, 141\%; cortex 159\%) (Fig. 5). Although there was some BBB disruption in the albumin-treated rats, in general, there appears to be considerably less BBB breakdown after albumin treatment.

At $28 \mathrm{~d}$, IgG staining within the striatum was difficult to visualize due to extensive tissue vacuolization; however, the cortex appeared to be less affected (Fig. 5). In saline- and albumin-treated rat pups, IgG staining was not significantly elevated in the ischemic compared with the contralateral cortex, suggesting that the BBB integrity had been reestablished. In 28-d tissue, differences between saline- and albumin-treated pups were not significant.

\section{DISCUSSION}

The current study was designed to assess the efficacy of albumin as a neuroprotective agent for neonatal stroke. The key findings can be summarized as follows: (1) no visual neuroimaging changes were observed between saline- and albumin-treated animals, (2) a transient increase in vasogenic edema (increased T2 values) was observed in ischemic regions of albumin-treated animals at 3-7 d after injury, (3) there was increased water mobility (increased ADC) present in the ischemic regions of the albumin animals at 14-28 d after injury, (4) there was no difference in infarct volume between albumin and saline animals, (5) both groups had similar histologic patterns of neuronal cell death and tissue loss, (6) albumin animals had significantly less BBB breakdown at $3 \mathrm{~d}$ compared with saline animals, and (7) neurologic outcomes were not significantly improved in albumin animals. Thus, while albumin appears to improve subtle measures of ischemia in the neonatal rat, it does not dramatically reduce infarct size to the same degree as adult stroke models of focal $(3,4,6,25)$ or global cerebral ischemia (26).

The neuroprotective effect of albumin treatment in adult stroke models. Studies of cerebral ischemia in adults have shown that albumin neuroprotection is mediated via multiple mechanisms $(3,4,6,25)$. When albumin remains intravascular, it increases the plasma oncotic pressure, resulting in hemodi- 
lution, reduced blood viscosity, and reduced cerebral edema, effects that are beneficial to ischemic tissue. If there is postischemic BBB disruption, albumin may enter brain tissue, potentially lessening these oncotic neuroprotective effects. However, this mechanism has been questioned as poststroke BBB disruption does occur (27), potentially lessening its neuroprotective effect and because other colloids such as pentastarch are neuroprotective without causing hemodilution. Other potential roles for albumin include inhibition of apoptosis of endothelial cells (28) that mediate its transcytosis and endocytosis $(29,30)$ and as a major antioxidant defense $(31,32)$ that binds to copper ions, inhibiting copper iondependent lipid peroxidation and the subsequent formation of highly reactive hydroxyl radicals $(2,32)$. Albumin also plays a critical role in the transport of fatty acids $(33,34)$ and in the binding of metabolites and drugs (35).

BBB damage in neonatal stroke. At $24 \mathrm{~h}$ post-stroke, BBB disruption in our saline-treated neonatal rats $(163 \%$ in cortex; $273 \%$ in striatum) was similar to that observed in an adult rodent stroke model in which Evans Blue was used (311\%) (27). Our results showed significantly less IgG staining in the striatum and cortex of the albumin treatment group at $3 \mathrm{~d}$. Although the influence of albumin on the formation of cerebral edema is still debated (36,37), transudation of albumin into brain tissues might increase and enhance the retention of intraparenchymal fluid within ischemic areas $(38,39)$, which could result in increased T2 in these tissues (Figs. 2 and 5), similar to our observations. Long-term, the early increased water retention could lead to altered tissue composition such that there is greater water mobility in the injured tissue in albumin-treated animals. Our increased ADC values at 14-28 d would support such a possible scenario.

The exact mechanisms responsible for BBB disruption following focal ischemia/reperfusion remain unclear, but the release of oxygen free radicals (40), nitric oxides, and proteases (41) has been implicated. Reperfusion after transient focal ischemia exacerbates brain edema formation, presumably by further BBB disruption (42), often due to increased vascular permeability $(39,43)$. Our findings support the notion that albumin may decrease BBB permeability via an unknown mechanism.

Neuroimaging of neonatal ischemia. We have previously described the temporal evolution of transient stroke in the neonatal rat using high-field MRI (21). In the present study, we have extended these findings by quantitative evaluation of $\mathrm{T} 2(\mathrm{~ms})$ and $\mathrm{ADC}\left(\mathrm{mm}^{2} / \mathrm{s}\right)$ in saline- and albumin-treated animals. We show a temporal increase in $\mathrm{T} 2$ values in the ischemic hemisphere that is significantly elevated in albumin compared with saline-treated animals. Increased T2WI is considered a marker of vasogenic edema (44). In the albumintreated group, the increased T2 values at $1-7 \mathrm{~d}$ (Fig. 2) is consistent with increased vasogenic edema. The almost twofold elevation of $\mathrm{T} 2$ in the ischemic striatum compared with cortex illustrates that this model results primarily in striatal injury, consistent with previous studies $(21,45)$.

DWI and quantitative ADC values can provide insights into water mobility. The decreased ADC in the ipsilateral striatum and cortex at $<3 \mathrm{~d}$ support the concept of cytotoxic edema formation. A previous study using an adult rat stroke model showed preservation of ADC values in ischemic and contralateral brain regions (4) after albumin treatment; a finding not found in the present neonatal stroke study. The findings bespeak a lack of therapeutic effect of albumin treatment in reducing either vasogenic or cytotoxic edema in our neonatal tfMCAO model.

Neurobehavioral alterations. Lack of neurobehavioral improvement in the albumin-treated group also did not support efficacy of albumin treatment. However, the lack of improvement could be due to the fact that our rat pups were $10 \mathrm{~d}$ old at the initiation of tfMCAO and had a very limited repertoire of behaviors that could be tested (21).

In summary, although the treatment of neonatal ischemia with albumin did not reduce infarct size, albumin-treated animals had significantly lower permeability of the BBB. Thus, one of the protective mechanisms for albumin may involve altering the permeability of the BBB. Future studies are still needed to elucidate the potential for albumin therapy in neonates. Our findings suggest that we should not assume that neuroprotective agents in adult stroke models would have similar therapeutic efficacy in the neonate. More importantly, they emphasize that postischemic mechanisms of injury and repair in newborns are likely to be different from in adults.

Acknowledgments. The authors thank Mrs. M. F. Hamou for assistance with IgG immunohistochemistry. The authors are grateful to Drs. D. Michelson and B. Bartnik for helpful reviews of the manuscript.

\section{REFERENCES}

1. Lynch JK, Nelson KB 2001 Epidemiology of perinatal stroke. Curr Opin Pediatr 13:499-505

2. Emerson TE Jr 1989 Unique features of albumin: a brief review. Crit Care Med 17:690-694

3. Belayev L, Busto R, Zhao W, Clemens J, Ginsberg M 1997 Effect of delayed albumin hemodilution on infarction volume and brain edema after transient middle cerebral artery occlusion in rats. J Neurosurg 87:595-601

4. Belayev L, Zhao W, Pattany P, Weaver G, Huh P, Lin B, Busto R, Ginsberg M 1998 Diffusion-weighted magnetic resonance imaging confirms marked neuroprotective efficacy of albumin therapy in focal cerebral ischemia. Stroke 29:2587-2599

5. Huh PW, Belayev L, Zhao W, Busto R, Saul I, Ginsberg MD 1998 The effect of high-dose albumin therapy on local cerebral perfusion after transient focal cerebral ischemia in rats. Brain Res 804:105-113

6. Belayev L, Liu Y, Weizhao Z, Busto R, Ginsberg M 2001 Human albumin therapy of acute ischemic stroke: marked neuroprotective efficacy at moderate doses and with a broad therapeutic window. Stroke 32:553-560

7. Heros RC, Korosue K 1989 Hemodilution for cerebral ischemia. Stroke 20:423-427

8. Cole DJ, Drummond JC, Patel PM, Marcantonio S 1994 Effects of viscosity and oxygen content on cerebral blood flow in ischemic and normal rat brain. J Neurol Sci 124:15-20

9. Belayev L, Saul I, Busto R, Danielyan K, Vigdorchik A, Khoutorova L, Ginsberg MD 2005 Albumin treatment reduces neurological deficit and protects blood-brain barrier integrity after acute intracortical hematoma in the rat. Stroke 36:326-331

10. Halliwell B, Gutteridge JM 1990 The antioxidants of human extracellular fluids. Arch Biochem Biophys 280:1-8

11. Rodriguez de Turco EB, Belayev L, Liu Y, Busto R, Parkins N, Bazan NG, Ginsberg MD 2002 Systemic fatty acid responses to transient focal cerebral ischemia: influence of neuroprotectant therapy with human albumin. J Neurochem 83:515-524

12. Keaney JF Jr, Simon DI, Stamler JS, Jaraki O, Scharfstein J, Vita JA, Loscalzo J 1993 NO forms an adduct with serum albumin that has endothelium-derived relaxing factor-like properties. J Clin Invest 91:1582-1589

13. Tabernero A, Medina A, Sanchez-Abarca LI, Lavado E, Medina JM 1999 The effect of albumin on astrocyte energy metabolism is not brought about through the control of cytosolic $\mathrm{Ca} 2+$ concentrations but by free-fatty acid sequestration. Glia 25:1-9

14. Ginsberg MD, Hill MD, Palesch YY, Ryckborst KJ, Tamariz D 2006 The ALIAS Pilot Trial: a dose-escalation and safety study of albumin therapy for acute ischemic stroke. I: Physiological responses and safety results. Stroke 37:2100-2106

15. Palesch YY, Hill MD, Ryckborst KJ, Tamariz D, Ginsberg MD 2006 The ALIAS Pilot Trial: a dose-escalation and safety study of albumin therapy for acute ischemic stroke. II: Neurologic outcome and efficacy analysis. Stroke 37:2107-2114 
16. Ginsberg MD, Palesch YY, Hill MD 2006 The ALIAS (ALbumin In Acute Stroke) Phase III randomized multicentre clinical trial: design and progress report. Biochem Soc Trans 34:1323-1326

17. Greenough A 1998 Use and misuse of albumin infusions in neonatal care. Eur J Pediatr 157:699-702

18. Uhing MR 2004 The albumin controversy. Clin Perinatol 31:475-488

19. Evans N 2003 Volume expansion during neonatal intensive care: do we know what we are doing? Semin Neonatol 8:315-323

20. Ashwal S, Cole DJ, Osborne S, Osborne TN, Pearce WJ 1995 A new model of neonatal stroke: reversible middle cerebral artery occlusion in the rat pup. Pediatr Neurol 12:191-196

21. Ashwal S, Tone B, Tian HR, Chong S, Obenaus A 2006 Serial magnetic resonance imaging in a rat pup filament stroke model. Exp Neurol 202:294-301

22. Bartnik BL, Kendall EJ, Obenaus A 2001 Cortical devascularization: quantitative diffusion weighted magnetic resonance imaging and histological findings. Brain Res 915:133-142

23. De Ryck M, Van Reempts J, Borgers M, Wauquier A, Janssen PA 1989 Photochemical stroke model: flunarizine prevents sensorimotor deficits after neocortical infarcts in rats. Stroke 20:1383-1390

24. Moser VC 1998 EPA/AIHC Training video and reference manual for a functional observational battery. Joseph F. Ross, Proctor U.S. Environmental Protection Agency

25. Belayev L, Pinard E, Nallet H, Seylaz J, Liu Y, Riyamongkol P, Zhao W, Busto R, Ginsberg MD 2002 Albumin therapy of transient focal cerebral ischemia: in vivo analysis of dynamic microvascular responses. Stroke 33:1077-1084

26. Belayev L, Saul I, Huh PW, Finotti N, Zhao W, Busto R, Ginsberg MD 1999 Neuroprotective effect of high-dose albumin therapy against global ischemic brain injury in rats. Brain Res 845:107-111

27. Belayev L, Busto R, Zhao W, Ginsberg MD 1996 Quantitative evaluation of blood-brain barrier permeability following middle cerebral artery occlusion in rats. Brain Res 739:88-96

28. Zoellner H, Hofler M, Beckmann R, Hufnagl P, Vanyek E, Bielek E, Wojta J, Fabry A, Lockie S, Binder BR 1996 Serum albumin is a specific inhibitor of apoptosis in human endothelial cells. J Cell Sci 109:2571-2580

29. Schnitzer JE, Sung A, Horvat R, Bravo J 1992 Preferential interaction of albuminbinding proteins, gp30 and gp18, with conformationally modified albumins. Presence in many cells and tissues with a possible role in catabolism. J Biol Chem 267:24544-24553

30. Antohe F, Dobrila L, Heltianu C, Simionescu N, Simionescu M 1993 Albuminbinding proteins function in the receptor-mediated binding and transcytosis of albumin across cultured endothelial cells. Eur J Cell Biol 60:268-275
31. Wasil M, Halliwell B, Hutchison DC, Baum H 1987 The antioxidant action of human extracellular fluids. Effect of human serum and its protein components on the inactivation of alpha 1-antiproteinase by hypochlorous acid and by hydrogen peroxide. Biochem J 243:219-223

32. Halliwell B 1988 Albumin — an important extracellular antioxidant? Biochem Pharmacol 37:569-571

33. Curry S, Mandelkow H, Brick P, Franks N 1998 Crystal structure of human serum albumin complexed with fatty acid reveals an asymmetric distribution of binding sites. Nat Struct Biol 5:827-835

34. Trigatti BL, Gerber GE 1995 A direct role for serum albumin in the cellular uptake of long-chain fatty acids. Biochem J 308:155-159

35. Koch-Weser J, Sellers EM 1976 Binding of drugs to serum albumin (first of two parts). N Engl J Med 294:311-316

36. Menzies SA, Hoff JT, Betz AL 1990 Extravasation of albumin in ischaemic brain oedema. Acta Neurochir Suppl (Wien) 51:220-222

37. Kuroiwa T, Shibutani M, Okeda R 1988 Blood-brain barrier disruption and exacerbation of ischemic brain edema after restoration of blood flow in experimental focal cerebral ischemia. Acta Neuropathol (Berl) 76:62-70

38. Young W, Rappaport ZH, Chalif DJ, Flamm ES 1987 Regional brain sodium, potassium, and water changes in the rat middle cerebral artery occlusion model of ischemia. Stroke 18:751-759

39. Hatashita S, Hoff JT 1990 Brain edema and cerebrovascular permeability during cerebral ischemia in rats. Stroke 21:582-588

40. Tuor UI, Chumas PD, Del Bigio MR 1995 Prevention of hypoxic-ischemic damage with dexamethasone is dependent on age and not influenced by fasting. Exp Neurol 132:116-122

41. Muramatsu K, Fukuda A, Togari H, Wada Y, Nishino H 1997 Vulnerability to cerebral hypoxic-ischemic insult in neonatal but not in adult rats is in parallel with disruption of the blood-brain barrier. Stroke 28:2281-2288

42. Yang GY, Betz AL 1994 Reperfusion-induced injury to the blood-brain barrier after middle cerebral artery occlusion in rats. Stroke 25:1658-1664

43. Abraham CS, Harada N, Deli MA, Niwa M 2002 Transient forebrain ischemia increases the blood-brain barrier permeability for albumin in stroke-prone spontaneously hypertensive rats. Cell Mol Neurobiol 22:455-462

44. Qiao M, Malisza KL, Del Bigio MR, Tuor UI 2001 Correlation of cerebral hypoxic-ischemic T2 changes with tissue alterations in water content and protein extravasation. Stroke 32:958-963

45. Memezawa H, Smith ML, Siesjo BK 1992 Penumbral tissues salvaged by reperfusion following middle cerebral artery occlusion in rats. Stroke 23:552559 